\title{
Utilização de óleo de moringa na cicatrização de feridas cutâneas em ratos
}

\section{Utilization de moringa oil in cutaneous wound healing in rats}

\section{Utilización de aceite de moringa en cicatrización cutánea de heridas en ratas}

Leonardo Luca Luciano

ORCID: https://orcid.org/0000-0001-8359-3558 Universidade Federal de Alfenas, Brasil E-mail: leonardo.luciano@sou.unifal-mg.edu.br

Evelise Aline Soares

ORCID: https://orcid.org/0000-0001-7838-687X Universidade Federal de Alfenas, Brasil

E-mail: evelise.anatomia@gmail.com

José Antonio Dias Garcia

ORCID: https://orcid.org/0000-0002-4024-3045

Universidade José do Rosário Vellano, Brasil Instituto Federal de Educação Ciência e Tecnologia do Sul de Minas Gerais, Brasil

E-mail: jadiasgarcia@gmail.com

Andréa Aparecida Pereira

ORCID: https://orcid.org/0000-0003-3162-4994

Universidade José do Rosário Vellano, Brasil

E-mail: aapp810@gmail.com

Adélia Pereira Miranda

ORCID: https://orcid.org/0000-0003-1782-9504 Instituto Federal de Educação, Ciência e Tecnologia Catarinense, Brasil

Email: adelia.miranda@ifc.edu.br

Délcio Bueno da Silva

ORCID: https://orcid.org/0000-0002-1248-5282 Instituto Federal de Educação, Ciência e Tecnologia do Sul de Minas Gerais, Brasil

E-mail: delcio.silva@muz.ifsuldeminas.edu.br

Aline Fernandes

ORCID: https://orcid.org/0000-0002-1274-6147

Universidade José do Rosário Vellano, Brasil

E-mail: aline.nands@hotmail.com

Thiago Donizeth da Silva

ORCID: https://orcid.org/0000-0002-5039-6651

Universidade José do Rosário Vellano, Brasil

E-mail: odontothiagosilva@gmail.com

Samuel José Fernandes de Lima

ORCID: https://orcid.org/0000-0001-9725-1284

Universidade José do Rosário Vellano, Brasil

E-mail: samuelfvet@hotmail.com

Erika Kristina Incerpi Garcia

ORCID: https://orcid.org/0000-0002-4259-2353

Universidade Federal de Alfenas, Brasil

E-mail: erika.garcia@unifal-mg.edu.br

Ciderleia Castro de Lima

ORCID: https://orcid.org/0000-0002-7737-3935

Universidade José do Rosário Vellano, Brasil

E-mail: ciderleiacastro@yahoo.com.br

\section{Resumo}

Introdução: A moringa é uma planta tropical pertencente à família Moringaceae e apresenta propriedades cicatrizantes pouco conhecidas. Objetivo: avaliar o efeito do óleo de moringa (Moringa oleífera L.) na cicatrização cutânea em ratos (Rattus novergicus). Metodologia: Foram utilizados 45 ratos (Rattus norvegicus), wistar, com três meses de idade, divididos em três tratamentos: GCN (grupo controle negativo): aplicação de creme não iônico; GOM (grupo óleo de moringa): adição de $10 \%$ do óleo de moringa ao creme não iônico; GCP (grupo controle positivo): aplicação de creme à base de sulfadiazina de prata a $1 \%$. Os ratos sofreram uma incisão de $1,0 \mathrm{~cm}$ circular na região dorsocervical e as feridas foram tratadas com os cremes. Resultados: Foi observada a evolução do processo cicatricial e medido o diâmetro das feridas. No $3^{\circ}, 7^{\circ}$ e $14^{\circ}$ dia do experimento, foram sacrificados cinco animais de cada grupo para a realização da contagem de macrófagos, neovasos e fibroblasto. A contagem de macrófagos mostrou aumento $(\mathrm{p}<0,05)$ após sete dias de aplicação dos cremes em todos os tratamentos. Os neovasos e fibroblastos não aumentaram (p>0,05) após sete dias de aplicação dos cremes nos tratamentos GCN e GCP em relação a três dias após início das 
aplicações, observando-se aumento $(\mathrm{p}<0,05)$ somente no tratamento GOM. Conclusão: As evidências obtidas mostraram que a aplicação tópica de creme acrescido com $10 \%$ de óleo de moringa em pele lesada influenciou em eventos celulares, otimizando a reparação tecidual e atenuando o processo inflamatório.

Palavras-chave: Óleo de moringa; Cicatrização; Reparação tecidual.

\begin{abstract}
Introduction: Moringa is a tropical plant belonging to the Moringaceae family and has little-known healing properties. Objective: to evaluate the effect of moringa oil (Moringa oleífera L.) on skin healing in rats (Rattus novergicus). Methodology: 45 wistar rats (Rattus norvegicus), three months old, were used, divided into three treatments: GCN (negative control group): application of non-ionic cream; GOM (moringa oil group): addition of 10\% of moringa oil to the non-ionic cream; GCP (positive control group): application of cream based on $1 \%$ silver sulfadiazine. The rats suffered a $1.0 \mathrm{~cm}$ circular incision in the dorsocervical region and the wounds were treated with the creams. Results: The evolution of the healing process was observed and the diameter of the wounds was measured. On the 3rd, 7th and 14th day of the experiment, five animals from each group were sacrificed for macrophage, neovessel and fibroblast counting. The macrophage count showed an increase $(\mathrm{p}<0.05)$ after seven days of applying the creams in all treatments. Neovessels and fibroblasts did not increase ( $p>0.05$ ) after seven days of application of the creams in the GCN and GCP treatments compared to three days after the beginning of the applications, with an increase $(\mathrm{p}<0.05)$ being observed only in the GOM treatment. Conclusion: The evidence obtained showed that the topical application of cream plus $10 \%$ moringa oil on injured skin influenced cellular events, optimizing tissue repair and attenuating the inflammatory process.
\end{abstract}

Keywords: Moringa oil; Healing; Tissue repair.

\title{
Resumen
}

Introducción: Moringa es una planta tropical que pertenece a la familia Moringaceae y tiene propiedades curativas poco conocidas. Objetivo: evaluar el efecto del aceite de moringa (Moringa oleífera L.) en la cicatrización de la piel en ratas (Rattus novergicus). Metodología: se utilizaron 45 ratas wistar (Rattus norvegicus), de tres meses de edad, divididas en tres tratamientos: GCN (grupo control negativo): aplicación de crema no iónica; GOM (grupo de aceite de moringa): adición de un $10 \%$ de aceite de moringa a la crema no iónica; GCP (grupo control positivo): aplicación de crema a base de sulfadiazina de plata al 1\%. Las ratas sufrieron una incisión circular de 1,0 cm en la región dorsocervical y las heridas se trataron con las cremas. Resultados: Se observó la evolución del proceso de cicatrización y se midió el diámetro de las heridas. Los días 3, 7 y 14 del experimento, se sacrificaron cinco animales de cada grupo para el recuento de macrófagos, neovasos y fibroblastos. El recuento de macrófagos mostró un aumento ( $\mathrm{p}<0,05)$ a los siete días de aplicar las cremas en todos los tratamientos. Los neovasos y fibroblastos no aumentaron ( $>$ > 0.05) después de siete días de aplicación de las cremas en los tratamientos GCN y GCP en comparación con tres días después del inicio de las aplicaciones, observándose un aumento ( $p<0.05)$ solo en el tratamiento GOM. Conclusión: La evidencia obtenida mostró que la aplicación tópica de crema más aceite de moringa al 10\% sobre la piel lesionada influyó en los eventos celulares, optimizando la reparación tisular y atenuando el proceso inflamatorio. Palabras clave: Aceite de moringa; Curación; Reparación de tejidos.

\section{Introdução}

A medicina alternativa aplicada através de plantas é usada por humanos desde tempos remotos auxiliando na cura de diversas doenças. Foi por meio do tratamento com as plantas medicinais que surgiu a Fitoterapia, cuja origem grega $($ phito $=$ planta e terapeias = tratamento) se caracteriza como a terapêutica por meio de plantas frescas, secas e seus preparados (Aguiar, 2010). Nesta perspectiva o gênero Moringa oleifera L. apresenta grande importância medicinal, pelo fato de possuir mais de 14 espécies com propriedades terapêuticas descritas.

A moringa é uma planta tropical pertencente à família Moringaceae, nativa da Índia que foi introduzida no Brasil por volta de 1950, sendo encontrada na região Nordeste. As sementes contêm um óleo, na Ásia também conhecido como óleo de Ben, que pode ser usado para cozinhar, confecção de sabão, na fabricação de cosméticos, pesquisas para indústria farmacêutica, no tratamento de água por floculação e sedimentação e como fixador de flagrâncias florais tem a propriedade de não adquirir ranço. A história da moringa como planta medicinal data de $150 \mathrm{a}$. C. Provas históricas revelam que antigos reis e rainhas usavam as folhas e os frutos de moringa na sua dieta para manter a mente alerta e a pele saudável (Almeida, 2018). Em virtude da fácil acessibilidade, o uso de plantas medicinais tem sido difundido em diferentes povos do mundo, sendo empregada até os dias atuais com intuito de melhorar a qualidade de vida e manutenção da saúde (Alencar et al., 2019). 
Dentre os compostos antimicrobianos presentes na moringa estão a pterygospermina e isotiocianato de benzila (Fahey, 2005) e as lectinas (Kou et al., 2018). Segundo Kou et al. (2018), a lectina solúvel em água isolada do extrato de sementes de M. oleifera tem efeitos inibitórios sobre o crescimento, sobrevivência e permeabilidade celular de múltiplas espécies de bactérias patológicas. Sugere-se que o mecanismo de ação é a alteração da permeabilidade da parede celular decorrente da interação da lectina com peptidoglicanos da parede celular (Santi-gadelha et al., 2006; Oliveira, 2008). As interações entre lectinas e açúcares desempenham papéis importantes em vários processos biológicos e medeiam uma ampla gama de atividades biológicas, incluindo atividades antibacterianas e antibiofilme (Klafke et al., 2013; Dias et al., 2015). Sendo assim, são eficazes contra bactérias formadoras de biofilme, impedindo fortemente a fixação bacteriana e formação de biofilme de Bacillus sp., sem interferir na integridade da membrana celular (Moura et al., 2017). A Moringa olifera é um exemplo de plantas ricas em flavonoides e extensamente utilizadas no tratamento de feridas (Ghosh \& Gaba, 2013).

De acordo com Muhammad et al. (2013) o extrato metanólico Moringa oleífera e sua fracção aquosa causaram aumentos na proliferação e migração em fibroblastos, a presença de flavonoides, na fração aquosa e no extrato metanólico de M. olifera, pode sugerir atividade cicatrizante de Moringa oleífera. Fokou et al. (2015) identificou que o uso do o extrato de folhas de possui moléculas antimicobacterianas para combater a infecção, o que permitiu uma mais rápida cicatrização. Segundo um estudo proposto por Andrade et al. (2020), a aplicação da fração aquosa da M. oleifera nas feridas de ratos sob condição hiperglicêmica revelou melhora da cicatrização, inibindo principalmente o crescimento de Staphylococcus aureus e Pseudomonas aeruginosa com uma CIM (concentração inibitória mínima) de 3,125 $\mu \mathrm{g} / \mathrm{mL}$, além de Escherichia coli com uma CIM de $6,25 \mu \mathrm{g} / \mathrm{mL}$.

Mediante as possíveis ações benéficas do uso da moringa sobre a cicatrização de pele e devido à escassez de trabalho que avaliam os efeitos do uso do óleo de moringa o presente estudo teve por objetivo avaliar o efeito cicatrizante do óleo de moringa (Moringa oleífera L.) na cicatrização cutânea em ratos (Rattus novergicus).

\section{Metodologia}

\subsection{Princípios éticos e protocolo animal}

O experimento foi realizado no Laboratório de Fitofármacos localizado na Faculdade de Agronomia da Universidade José do Rosário Vellano (UNIFENAS) campus de Alfenas obedecendo aos princípios éticos em experimentação animal preconizado pelo Colégio Brasileiro de Experimentação Animal - COBEA e aprovado pelo comitê de ética local, sob o número de protocolo 24A/2011.

Para a realização deste estudo, utilizou-se uma metodologia de natureza quantitativa em modelo experimental (Pereira et al., 2018). Foram utilizados 45 ratos (Rattus norvegicus), wistar, brancos, machos, com três meses de idade, pesando 270 \pm 30 g, obtidos do Biotério Central da UNIFENAS. Os animais foram divididos aleatoriamente em três grupos experimentais $(\mathrm{n}=15)$ :

- T1: Grupo controle negativo (GCN): aplicação de creme não iônico sobre a lesão.

- T2: Grupo óleo de moringa (GOM): adição de 10\% do óleo de moringa ao creme não iônico.

- T3: Grupo controle positivo (GCP): aplicação de creme à base de sulfadiazina de prata a $1 \%$.

\subsection{Obtenção do óleo de Moringa e produção do creme}

O óleo da semente da planta em estudo foi doado pela Universidade Federal Rural de Pernambuco e obtido por meio de extração mecânica, efetuada em prensa da marca Tecnal, modelo TE-098, conforme metodologia citada por Vasconcelos (2009). O creme não iônico e o creme com a adição de óleo de moringa foram manipulados no Laboratório de Manipulações Farmacêuticas do Curso de Farmácia - UNIFENAS campus de Alfenas. 
A base escolhida para se misturar ao óleo foi o creme devido a sua boa dispersão e penetração na pele. $\mathrm{O}$ creme não iônico se caracteriza como um placebo, ou seja, substância ou preparação inativa administrada para satisfazer a necessidade simbólica do paciente por terapia com medicamentos, e também é utilizada em estudos controlados para determinar a eficácia de fármacos (Oliveira, 2008). Teve também função de veículo e excipiente para o óleo de moringa, ou seja, correspondeu à substância mais ou menos inerte de uma fórmula medicamentosa, conferindo consistência adequada à mistura.

A fórmula do creme não iônico foi $10 \%$ de propilenoglicol; 0,05\% de EDTA; 0,15\% de metilparabeno. Já a fórmula do creme contendo óleo de moringa foi de $10 \%$ de polawax; $0,05 \%$ de BHT; $5 \%$ de óleo mineral; $0,05 \%$ de propilparabeno e $10 \%$ de óleo de moringa.

A sulfadiazina de prata também em forma de creme para maior absorção da pele foi escolhido para ser a substância usada no Grupo Controle Positivo (GCP), sendo a composição de cada 1,0 grama do creme: sulfadiazina de prata micronizada $10 \mathrm{mg}$, excipientes (álcool cetoestearílico, estearil éter, álcool oleílico etoxilado, metilparabeno, propilparabeno, vaselina, propilenoglicol, água deionizada) e q.s.p.1g.

\subsection{Procedimento cirúrgico e tratamento}

Os ratos foram alojados em gaiolas individuais e alimentados com ração comercial, triturada e moída e água ad libitum e o início do experimento ocorreu dia 05/10/2012 quando os animais foram lesados após antissepsia com uma incisão de aproximadamente $1,0 \mathrm{~cm}$ circular na região dorso-cervical. Para tanto, os ratos foram submetidos à anestesia com Xilasina ( $2 \%$ - 10 a $13 \mathrm{mg} / \mathrm{kg}$ de peso intraperitoneal I.P) associada a Quetamina ( $80 \mathrm{ml}-90 \mathrm{mg} / \mathrm{kg}$ de peso intraperitoneal I.P) e realizada depilação do local com creme depilatório Depi roll@ e remoção do excesso de creme usando soro fisiológico para uma extensão de mais ou menos quatro $\mathrm{cm}^{2}$. Após foi feita a incisão no centro da área epilada, aprofundou-se a incisão até a fáscia utilizando de tesoura e contida a hemostasia por compressão digital com gases. Após este procedimento foram feitos os tratamentos supracitados e a posologia escolhida foi a de $12 \mathrm{em} 12$ horas.

O experimento teve duração de dezoito dias e as feridas experimentais foram avaliadas clinicamente por um único observador. Durante todo o período, as feridas foram tratadas friccionando-se uma espátula delicadamente sobre o ferimento e deixando uma camada fina excedente de creme sobre esta. As feridas foram tratadas e observadas enquanto estavam dentro da gaiola, tal procedimento era importante para que se evitasse estresse dos animais e manipulasse-os menos possível. Assim sendo, as análises macroscópicas realizadas foram à observação da evolução do processo cicatricial e medição do diâmetro das feridas, em milímetros. Na Figura 1, é apresentada a incisão experimental realizada em um dos animais do experimento.

Figura 1. Rato com incisão tecidual experimental de aproximadamente 1,0 centímetro circular na região dorso-cervical na data da cirurgia (A) e 14 dias após a realização da incisão (B).

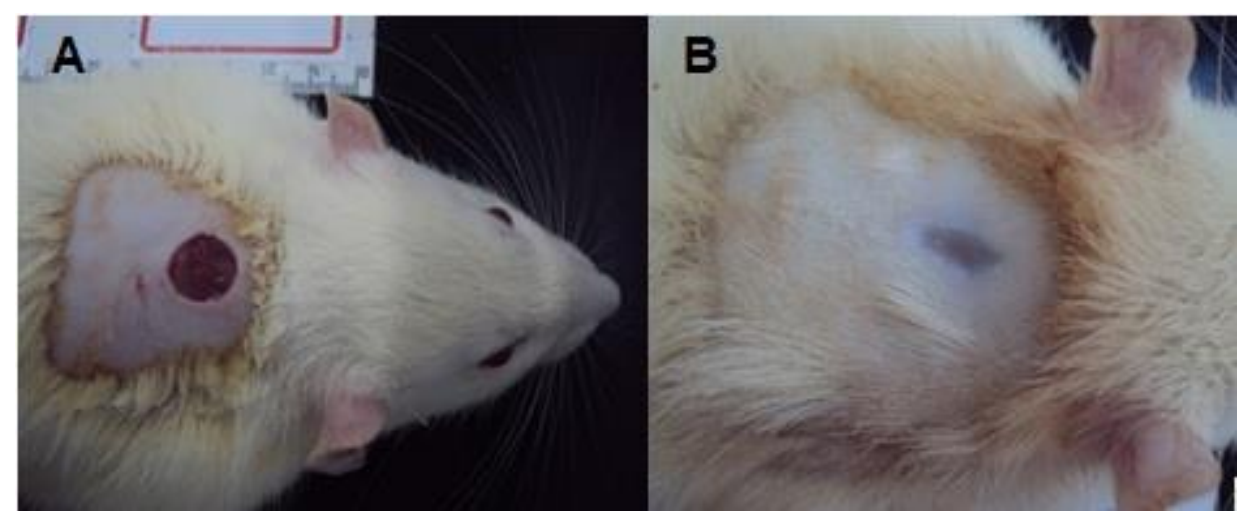

Fonte: Autores. 
O experimento começou no dia 18 dias com eutanásia dos últimos cinco animais do Tratamento 3 (GCP) em câmara de gás CO2. Para que depois pudessem ser realizados os cortes e posteriores análises microscópicas da cicatrização das lesões, sendo estas a contagem de macrófagos, neovasos e fibroblastos em lâminas histológicas.

\subsection{Processamento e análise histológica}

A técnica de preparação histológica consistiu na retirada de um fragmento de tecido em regeneração e a fixação feita a fim de evitar a possível destruição das células por autólise ou por bactérias. Isto explica o fato de terem sido coletados fragmentos dos tecidos logo após o sacrifício dos animais em estudo, pois além de impedir degenerações post mortem, a fixação visa endurecer os tecidos os tornando mais rígidos. No presente trabalho, foi usada formalina a $10 \%$ e, em seguida, a desidratação do tecido, diafanização a qual consiste no mergulho em agentes clarificantes, impregnação em parafina completa dos tecidos, inclusão da peça de parafina apara-se em bloco para ser levado ao micrótomo e colagem dos cortes nas lâminas, coloração com hematoxilina e eosina HE e, por fim, a montagem definitiva com lamínula utilizando bálsamo do Canadá para colar a lamínula sobre a lâmina.

Os cortes histológicos das laminas coradas com HE foram analisados com microscópio óptico com luz normal. As imagens histológicas foram capturadas por câmera digital com aumento da objetiva de 40 ou $400 \mathrm{X}$. Na contagem de macrófagos, neovasos e fibroblastos foram analisados um campo de cada corte histológico por Patologista Veterinária experiente comparando a morfologia e calculando a média do número de macrófagos, de neovasos e fibroblastos presentes.

\subsection{Estatística}

Os valores da contagem de macrófagos, de neovasos e de fibroblastos foram analisados e comparados através da análise de variância (ANOVA) seguida de teste Tukey, com significância de 5\%.

\section{Resultados e Discussão}

$\mathrm{Na}$ análise macroscópica das lesões, observou-se a evolução do processo cicatricial, verificando que as lesões inicialmente continham de 8,0 a 15,0 milímetros de diâmetro e no final do experimento, após 14 dias de lesão, possuíam por volta de 5,0 milímetros de diâmetro, conforme evidenciado na Figura 2. 
Figura 2. Animais do GOM (creme não iônico acrescido de 10\% de óleo de moringa) no dia da cirurgia experimental que causou lesão cutânea (A), três dias após (B), sete dias após (C) e 14 dias após início do tratamento tópico (D).

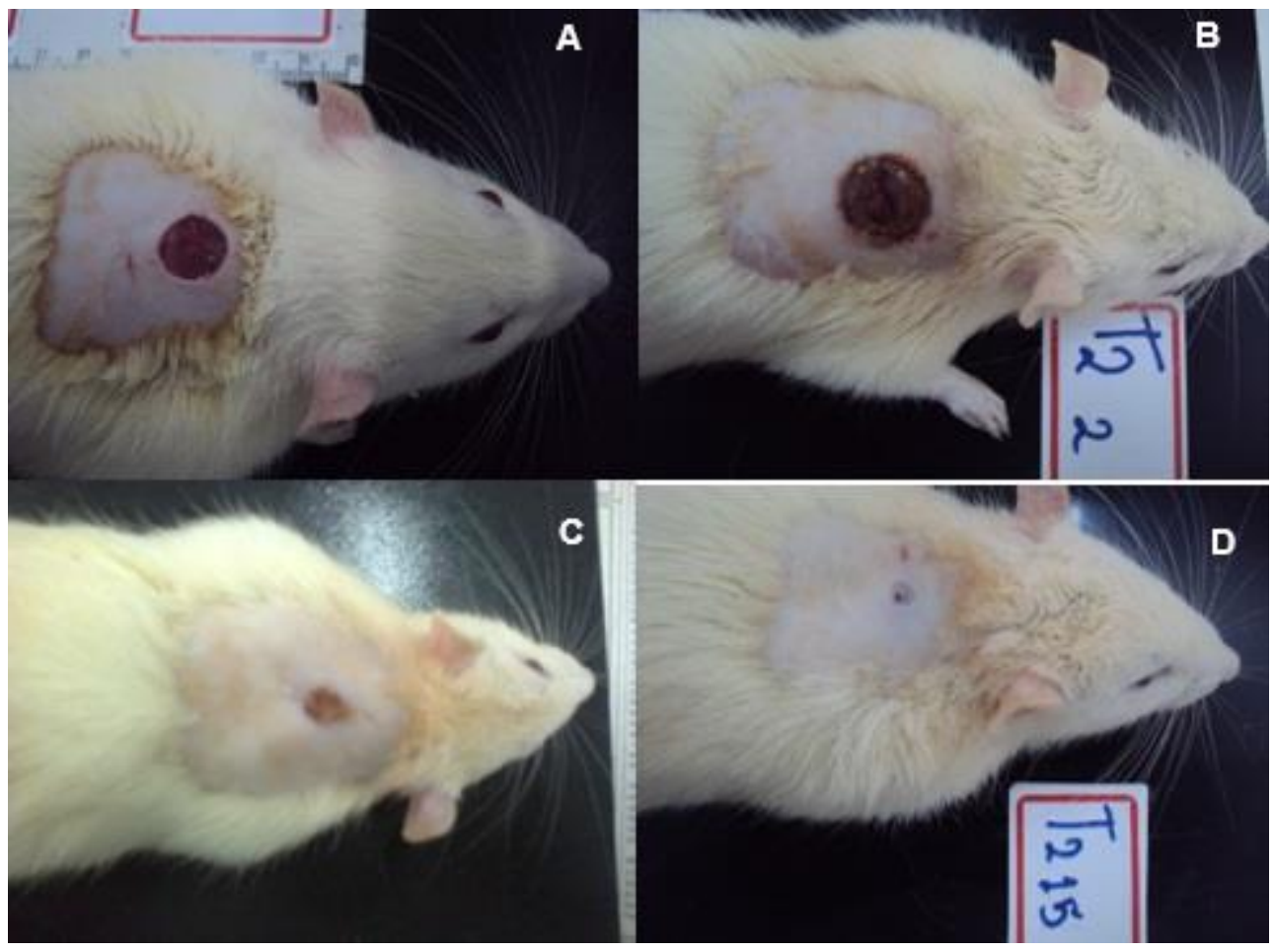

Fonte: Autores.

No grupo controle negativo (GCN), ou seja, no qual se aplicou o creme não-iônico sobre a lesão, a evolução da cicatrização foi considerada satisfatória, tendo em vista que neste grupo não foi utilizado nenhuma espécie de antibiótico e não teve intercorrências de infecções secundárias, visto que os veículos utilizados para confecção do creme não-iônico são emolientes e deixaram as feridas hidratadas.

No grupo no qual foi adicionado $10 \%$ do óleo de moringa ao creme não-iônico (GOM) a cicatrização foi bem sucedida em todas as fases do processo de reparo. Em três indivíduos deste tratamento, as lesões sempre estavam úmidas com leve presença de exsudato e quando formavam crostas estas saíam e o animal novamente voltava a sangrar. Acredita-se que tais ocorrências surgiram porque estes animais tinham mais apetite que os outros e observou-se que durante o experimento, estes ganharam peso e o espaço nos comedouro tornou-se insuficiente, acarretando atrito das feridas, o que ocasionou infecções secundárias. Além disso, segundo estudos de Bhattacharya et al. (2018) e Lambole et al. (2012), extratos de folha, polpa seca e sementes de Moringa oleifera L. mostraram um aumento significativo na resistência à quebra do tecido de granulação, diminuição na área de cicatriz e resistência à quebra da pele. Contrapondo, portanto, os dados evidenciados. Considerando o exposto estes indivíduos não foram analisados.

No grupo controle positivo (GCP), no qual se utilizou creme à base de sulfadiazina de prata a 1\% nas lesões dos ratos, as feridas tiveram cicatrização satisfatória com crostas sempre secas e sem formação de exsudatos. Esta droga foi relatada como eficaz no processo de cicatrização de feridas por induzir a epitelização e formação de tecido de granulação (Heyneman et al., 2016).

A análise histológica da lâmina de tecido de animal pertencente ao tratamento controle negativo, ou seja, no qual se aplicou o creme não-iônico sobre a lesão, observam-se hemácias evidenciando alguns vasos bem dispersados e fibroblastos bem distribuídos nas fibras colágenas indicando ativo processo reepitelização e de crescimento de tecido de granulação. Esse fato demonstra a evolução normal da fase proliferativa no processo cicatricial. É caracterizada por um acúmulo de células e 
tecido conjuntivo abundante. A ferida abrange fibroblastos, queratinócitos e células endoteliais. A matriz extracelular (MEE), incluindo proteoglicanos, ácido hialurônico, colágeno e elastina, forma um tecido de granulação para substituir a formação original do coágulo (Wang et al., 2018). Na Figura 3 está apresentado corte histológico de fragmento de tecido de um animal pertencente a este tratamento sacrificado sete dias após a lesão experimental e na Figura 4 a presença de neovasos, fibroblastos e macrófagos.

Figura 3. Análise histológica de tecido epitelial corado com HE em MO 40X de rato do grupo controle negativo (GCN), sacrificado sete dias após a lesão experimental.

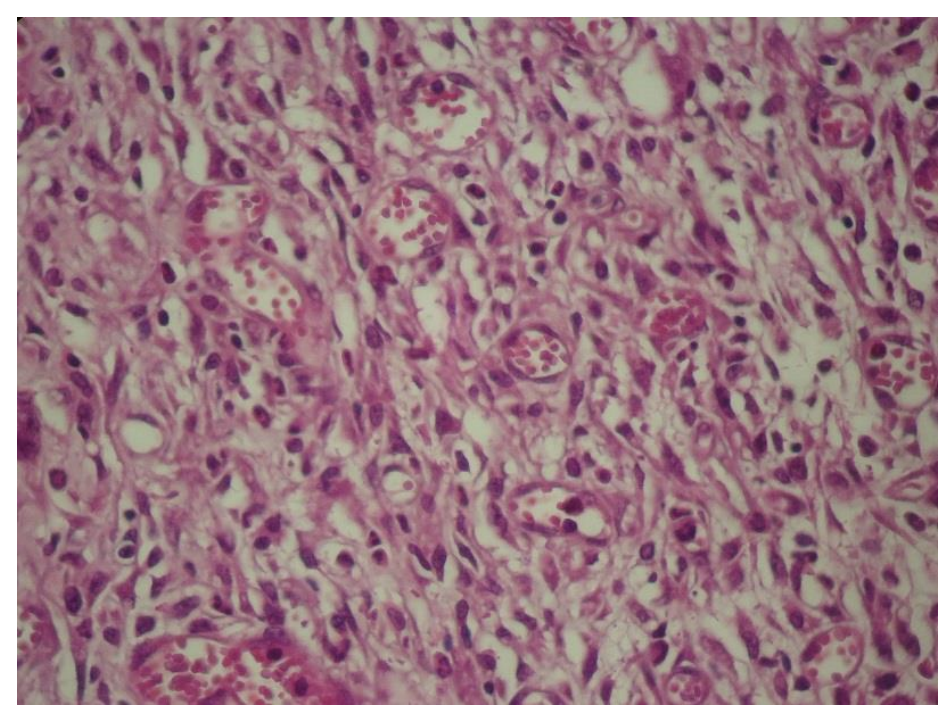

Fonte: Autores.

Figura 4. Análise histológica de tecido epitelial corado com HE em MO 40X de rato do grupo controle negativo (GCN), sacrificado sete dias após a lesão experimental. *Neovasos indicados por riscos laranja, fibroblastos indicados por riscos vermelhos e macrófagos por riscos verdes.

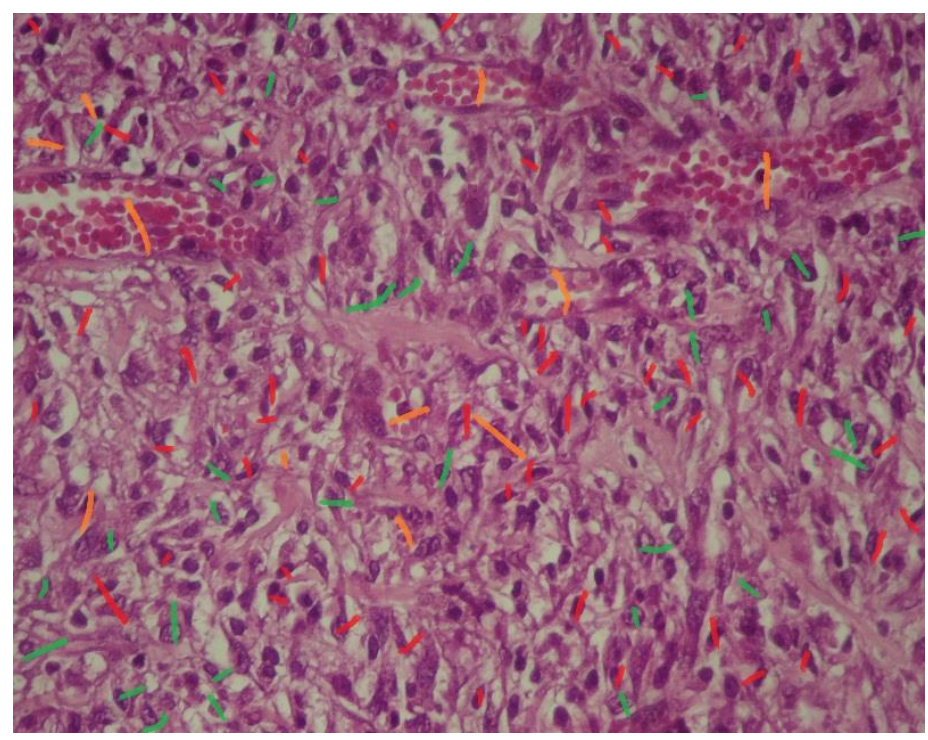

Fonte: Autores.

Na Figura 5 é apresentada a análise histológica da lâmina de tecido de animal pertencente ao tratamento com óleo de moringa, ou seja, no qual se aplicou o óleo de moringa associado ao creme não-iônico sobre a lesão. Nesta lâmina, são 
evidenciadas as hemácias localizadas em vasos e fibroblastos, porém mais distantes e organizados em fibras colágenas e também com presença de macrófagos. Na figura observa-se formação de neovasos, fibroblastos bem dispostos com muitas fibras colágenas e coloração basofílica, evidenciando claramente as estruturas nas quais estão presentes os macrófagos.

Figura 5. Análise histológica de tecido epitelial corado com HE em MO 40X. Rato tratado com creme não-iônico adicionado de 10\% de óleo de moringa (GOM), sacrificado sete dias após a lesão experimental.

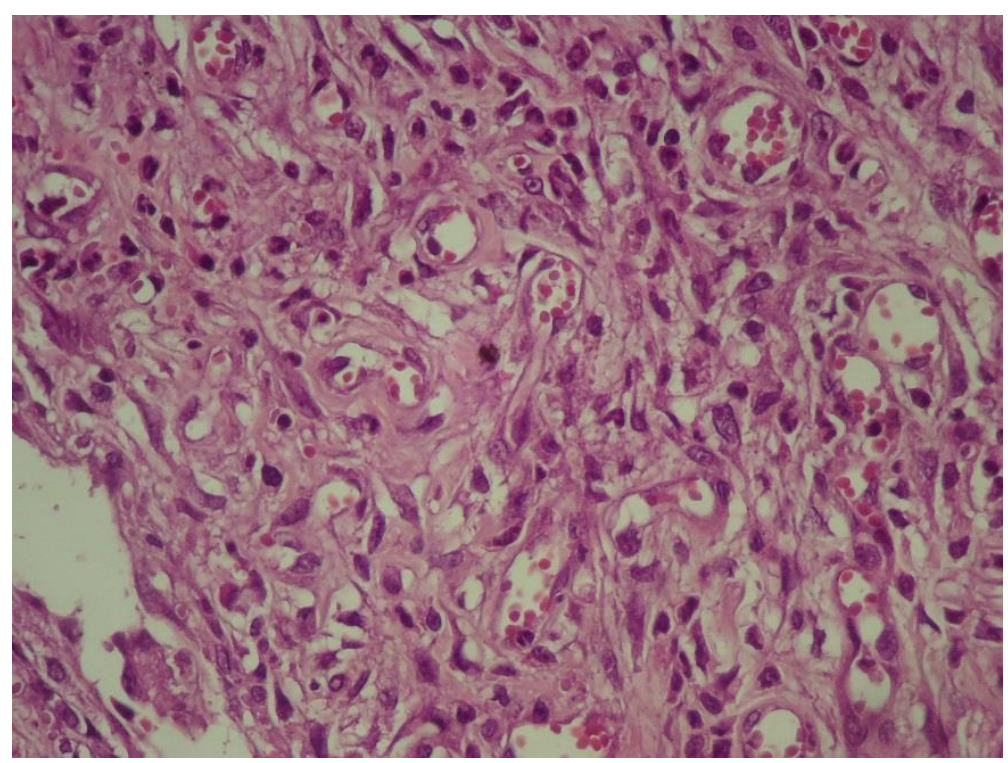

Fonte: Autores.

$\mathrm{Na}$ Tabela 1 são apresentados os números médios de macrófagos, neovasos e fibroblastos contados de lâminas histológicas de fragmentos de lesão de ratos submetidos aplicação de creme não-iônico sobre a lesão (GCN), ratos tratados com adição de $10 \%$ do óleo de moringa ao creme não iônico (GOM) e ratos tratados com creme à base de sulfadiazina de prata a 1\% (GCP) após três e sete dias de tratamento. Nas lâminas histológicas referentes ao décimo quarto dia não houve distinção de macrófagos, neovasos e fibroblastos por se tratar de cicatriz quase que completa, ou seja, madura e, por este motivo, não foi realizada a contagem de macrófagos, neovasos e fibroblastos.

Tabela 1. Números médios de macrófagos, neovasos e fibroblastos em lesão de ratos submetidos aplicação de creme não iônico (GCN), creme não iônico com adição de $10 \%$ do óleo de moringa (GOM) e creme à base de sulfadiazina de prata a $1 \%$ (GCP) após três e sete dias de tratamento.

\begin{tabular}{|c|c|c|c|c|}
\hline \multirow[t]{2}{*}{ Variáveis } & \multirow[t]{2}{*}{ Tempo pós-lesão } & \multicolumn{3}{|c|}{ Tratamentos } \\
\hline & & GCN & GOM & GCP \\
\hline & 3 dias & $10,9 \mathrm{Bab}$ & $8,3 \mathrm{Bb}$ & $17,6 \mathrm{Ba}$ \\
\hline \multicolumn{5}{|l|}{ Macrófagos/campo } \\
\hline & 7 dias & $22,0 \mathrm{Ab}$ & $33,6 \mathrm{Aa}$ & $32,1 \mathrm{Aa}$ \\
\hline
\end{tabular}

p tempo: 0,0010

p tratamentos: 0,0021 
p tempo x tratamento: 0,0057

*CV (\%) tempo: 25,92

tratamentos: 20,95

$\begin{array}{llrr}3 \text { dias } & 21,0 \mathrm{Aa} & 12,65 \mathrm{Bb} & 12,37 \mathrm{Ab} \\ 7 \text { dias } & 23,7 \mathrm{Aa} & 25,1 \mathrm{Aa} & 15,5 \mathrm{Ab}\end{array}$

p tempo: 0,0198

p tratamentos: 0,0061

p tempo x tratamento: 0,0781

*CV (\%) tempo: 24,13

tratamentos: 27,37

\begin{tabular}{|c|c|c|c|c|}
\hline \multirow{3}{*}{ Fibroblastos/campo } & 3 dias & $33,6 \mathrm{Aa}$ & $13,0 \mathrm{Ba}$ & $32,1 \mathrm{Aa}$ \\
\hline & & & & \\
\hline & 7 dias & 49,3 Aab & $73,8 \mathrm{Aa}$ & $41,5 \mathrm{Ab}$ \\
\hline
\end{tabular}

p tempo: 0,0030

p tratamentos: 0,6967

p tempo x tratamento: 0,0098

*CV (\%) tempo: 30,15

tratamentos: 43,72

*Coeficiente de Variação

${ }^{1}$ Médias seguidas de mesma letras maiúscula, na coluna, não diferem entre si pelo teste de Tukey, considerando significância de $5 \%$ e comparam tempo pós lesão.

${ }^{2}$ Médias seguidas de mesma letras minúscula, na linha, não diferem entre si pelo teste de Tukey, considerando significância de $5 \%$ e comparam tratamentos.

Fonte: Autores.

$\mathrm{Na}$ análise de macrófagos observa-se que houve aumento $(\mathrm{p}<0,05)$ destes após sete dias de aplicação dos cremes em todos os tratamentos. Três dias após início de aplicação dos cremes no GCP (Grupo Controle Positivo) observou-se maior $(\mathrm{p}<0,05)$ números de macrófagos e nos sete dias após aplicação dos cremes, os tratamentos efetivos $(\mathrm{p}<0,05)$ foram os tratamentos GOM e GCP.

O número de macrófagos em todos os tratamentos esteve em média abaixo de 40 de forma bem homogênea entre os três grupos sendo assim considerado que não houve nenhuma infecção durante a fase experimental somente sendo fisiológico e necessário para a cascata de inflamação e reparo tecidual. Essa 
fase é conhecida como fase inflamatória e leva cerca de 72 horas para terminar. Os neutrófilos são as primeiras células a aparecerem no local da lesão e fornecem um ambiente bom para a cicatrização. A seguir, os macrófagos se acumulam e facilitam a fagocitose de bactérias e danificam o tecido (Berman et al., 2017).

Analisando os neovasos observa-se que não houve aumento ( $>>0,05)$ destes após sete dias de aplicação dos cremes nos tratamentos GCN e GCP em relação ao terceiro dia após início das aplicações. Entretanto, no tratamento GOM observou-se aumento $(\mathrm{p}<0,05)$ no número de neovasos quando se compara sete dias com três dias de aplicação do creme não-iônico adicionado de óleo de moringa. Três dias após a aplicação dos cremes nas lesões observou-se maior número de neovasos no $\mathrm{GCN}(\mathrm{p}<0,05)$ e sete dias após aplicação dos cremes os tratamentos efetivos $(\mathrm{p}<0,05)$ foram o GCN e GOM diferindo estatisticamente do tratamento GCP.

O número de neovasos está homogêneo, entre os três tratamentos apresentando números abaixo de quarenta neovasos em cada animal.

Os fibroblastos não aumentaram ( $p>0,05)$ após sete dias de aplicação dos cremes nos tratamentos GCN e GCP em relação ao terceiro dia após início das aplicações, observando-se aumento $(\mathrm{p}<0,05)$ somente no tratamento GOM. Três dias após o início da aplicação dos cremes nas lesões não foram verificadas diferenças $(p>0,05)$ entre os tratamentos testados e sete dias após início das aplicações, o tratamento GOM foi estatisticamente superior ao GCP não diferindo, entretanto do GCN ( $p>0,05$ ) quanto à contagem de fibroblastos.

$\mathrm{Na}$ fase de fibroplasia, a partir do quarto dia ocorre a formação de tecido de granulação e começa uma lenta contração tecidual. Para que tais eventos ocorram, crescem capilares, vasos, macrófagos e fibroblastos principalmente, mas assim que o tempo passa os fibroblastos perdem a sua função e voltam a ser fibrócitos, os quais são células "velhas" que não sintetizam mais as fibras e nem matriz extracelular.

Os processos de cicatrização tecidual são fenômenos que podem ser divididos didaticamente em quatro fases. A primeira caracteriza-se por coagulação, inicialmente imediata logo após o trauma, caracterizada pela formação de um tampão hemostático primário (crosta hemato-fibrinosa), formado por plaquetas, ativação dos fatores de coagulação e liberação de mediadores químicos solúveis, responsáveis pelo desencadeamento dos estágios subsequentes.

Na segunda fase do processo de cicatrização tecidual ocorre a fase inflamatória, responsável por alterações vasculares e influxo de células inflamatórias (polimorfonucleares, macrófago e linfócito) para o sítio da lesão. A terceira fase é caracterizada pela proliferação de células endoteliais de pequenos vasos sanguíneos (angiogênese), fibroblastos e produção de matriz colágeno, responsáveis pela formação do tecido de granulação, e início da proliferação de células epiteliais das camadas basais. Por fim há a fase reparadora, responsável pela remodelagem tecidual, com a substituição do tecido de granulação por tecido 
conjuntivo denso e a recomposição celular da epiderme (Morgun et al., 2020; Martin \& Nunan et al., 2015; Bosanquet et al., 2014; Moura et al., 2020).

A grande quantidade de macrófagos, neovasos e fibroblastos no décimo quarto dia pós-lesão é justificada pelo fato de a retirada de fragmento de pele induzir a formação de solução de continuidade que é preenchida por fibrina, coágulo e exsudado inflamatório, formando a crosta que recobre a ferida. Assim sendo, a hipóxia tecidual crônica torna-se potente estimuladora da proliferação capilar na reparação tecidual e angiogênese, pois formando brotos endoteliais em contiguidade com vasos sanguíneos e com suas células proliferam intensamente, formam-se cordões sólidos e sinuosos que se canalizam permitindo o fluxo sanguíneo através deles (Martins et al., 2006) impedindo a contagem das células supracitadas 14 dias após aplicações dos cremes testados.

Ainda justificando as cicatrizações neste momento pós-lesão, Young et al. (2007) descrevem que os fibroblastos e miofibroblastos secretam componentes da matriz extracelular como substância fundamental e o colágeno para substituir a área danificada por material fibrocolagenoso. Esta é a base para formação de uma cicatriz fibrosa de colágeno, sendo que no decorrer do tempo, há uma remodelação do colágeno para minimizar sua resistência e uni-lo aos tecidos adjacentes formando a cicatrização por reparo.

\section{Conclusão}

As evidências obtidas nas contagens de macrófagos, neovasos e fibroblastos mostraram que a aplicação tópica de creme acrescido com $10 \%$ de óleo de moringa em pele lesada influenciou em eventos celulares, otimizando a reparação tecidual e diminuindo o processo inflamatório. Contudo, salienta-se que há uma escassez de estudos que avaliem os efeitos terapêuticos da Moringa oleífera em humanos. Por isso, é importante investir em pesquisas, principalmente ensaios clínicos, que esclareçam a maneira de preparação e administração dos metabólitos dessa planta, confirme os efeitos farmacológicos e sua segurança.

\section{Referências}

Aguiar, N. L. F. (2010). Avaliação do Potencial Antifúngico de Produto de Plantas em Cepas de Candida albican e Microsporun canis Isolados de Cães e Gatos: Um destaque para Moringa oleifera e Vernonia sp. 63 f. Dissertação (Mestrado em Medicina Veterinária) - Universidade Estadual do Ceará.

Alencar, E. M. et al. (2019). Estudo etnobotânico do conhecimento e uso das plantas medicinais no município de Buriticupu, Maranhão, Brasil. Revista Ibero-Americana de Ciências Ambientais. 10(6), 328-38.

Almeida, M. S. M. (2018). Moringa oleífera Lam. seus benefícios medicinais, nutricionais e avaliação de toxicidade. Dissertação de Mestrado, Universidade de Coimbra, Coimbra, Portugal.

Andrade, J. I. A. et al. (2020). Propriedades terapêuticas da Moringa oleífera Lam. no tratamento do diabetes mellitus. Research, Society and Development. 9(7), e485974270.

Berman, B. et al. (2017). Queloides e cicatrizes hipertróficas: fisiopatologia, classificação e tratamento. Dermatol Surg. 43(1), S3-S18.

Bhattacharya, A. et al. (2018). A Review of the Phytochemical and Pharmacological Characteristics of Moringa oleifera. Journal of pharmacy \& bioallied sciences. 10(4), 181-191. 
Bosanquet, D. C. et al. (2014). Wound duration and healing rates: cause or effect? Wound Repair Regen. 22(2), 143-50.

Dias, R. O. et al. (2015). Insights sobre lectinas de animais e plantas com atividades antimicrobianas. Moléculas. 20(1), 519-54.

Fahey J. W. (2005). Moringa oleifera: Uma revisão da evidencia médica para suas propriedades nutricionais, terapêuticos e profiláticos. Parte1. Departamento de Farmacologia e Ciências Moleculares. In: Lewis B. e Dorothy Cullman chemoprotection Cancer Center. 1-15.

Ghosh, P. K., \& Gaba, A. (2013). Phyto-Extracts in Wound Healing. Journal of Pharmacy \& Pharmaceutical Sciences. 16(5), 760-820.

Heyneman, A., et al. (2016). O papel da sulfadiazina de prata no tratamento conservador de queimaduras de espessura parcial: uma revisão sistemática. Burns. 42(7), 1377-1386.

Klafke, G. B., et al. (2013). Inibição da adesão inicial de bactérias orais por meio de uma lectina de Bauhinia variegata L. var. variegata expressa em Escherichia coli. J Appl Microbiol. 115(1), 1222 - 1230.

Kou, X., et al. (2018). Nutraceutical or pharmacological potential of Moringa oleífera Lam. Nutrients. 10(3), 343.

Lambole, V., et al. (2012). Effect of Moringa oleifera Lam. on normal and dexamethasone suppressed wound healing, Asian Pacific Journal of Tropical Biomedicine. 2(1), S219-S223.

Martin, P., \& Nunan, R. (2015). Cellular and molecular mechanisms of repair in acute and chronic wound healing. The British Journal of Dermatology. $173(2), 370-8$.

Martins, P. L. N., et al. (2006). Análise Comparativa da Cicatrização da Pele com o Uso Intraperitoneal de Extrato aquoso de Orbignya phalerata (Babaçu): Estudo controlado em ratos. Acta Cirúrgica Brasileira. 21(3).

Morgun, E. I., \& Vorotelyak E. A. (2020). Epidermal Stem Cells in Hair Follicle Cycling and Skin Regeneration: A View From the Perspective of Inflammation. Frontiers in cell and developmental biology. 8, 581697.

Moura, M. C. et al. (2017). Multi-effect of the water-soluble Moringa oleifera lectin against Serratia marcescens and Bacillus sp.: antibacterial, antibiofilm and anti-adhesive properties. J Appl Microbiol. 123(4):861-874.

Moura, W. P. F., et al. (2020). Efeito do gel a base de Moringa oleifera lam. como fitoterapia na cicatrização de feridas. Research, Society and Development. 9(11), e4109119957.

Muhammad, A. A., et al. (2013). In vitro wound healing potential and identification of bioactive compounds from Moringa oleifera Lam. BioMed research international. 1-10.

Fokou, P. V. T., et al. (2015). Ethnopharmacological reports on anti-Buruli ulcer medicinal plants in three West African countries. Journal of Ethnopharmacology. 297-311.

Oliveira, E. A. S. (2008). Farmacologia geral - histórico e evolução Conceitos de drogas e medicamentos - Aspectos legais Subdivisões da farmacologia Algumas definições básicas em farmacologia. - Bioensaio - Ensaio clínico. (Apostila n ${ }^{\circ} 01$ ).

Pereira, A. S., Shitsuka, D. M., Parreira, F. J., \& Shitsuka, R. (2018). Metodologia da pesquisa científica. Ed. UAB/NTE/UFSM. Recuperado de https://repositorio.ufsm.br/bitstream/handle/1/1582 4/Lic_Computacao_Metodologia-Pesquisa-Cientifica.pdf?sequence=1.

Santi-Gadelha, T. et al. (2006). Purification and biological effects of Araucaria angustifolia (Araucariaceae) seed lectin. Biochemical and Biophysical Research Communication. 350(1), 1050-5.

Vasconcelos, V. M. (2009). Caracterização físico-química do óleo de moringa oleifera lam por diferentes solventes. Encontro Nacional De Moringa, Universidade Federal de Sergipe, Aracaju, Brasil.

Wang, P. et al. (2018). Cicatrização de feridas. Jornal da Ordem dos Médicos Chinesa. 81(1), 94-101.

Young, B. et al. (2007). Histologia Funcional - Texto e Atlas em Cores. (5a ed.). Elsevier. 